\title{
Interventional treatment of pain in refractory angina. A review
}

\author{
Milos Dobias ${ }^{a}$, Pavel Michaleka, Petr Neuzil ${ }^{b}$, Martin Stritesky ${ }^{a}$, Paul Johnston ${ }^{c}$
}

\begin{abstract}
Background. Refractory angina is characterized by repeated attacks of chest pain in patients on maximal anti-anginal pharmacotherapy, with a professional conscensus that further surgical or radiological revascularization would be futile. Refractory angina is a serious but relatively uncommon health problem, with a reported incidence of approximately 30 patients per million people/year. In this condition simply treating the associated pain alone is important as this can improve exercise tolerance and quality of life.
\end{abstract}

Methods. An extensive literature search using five different medical databases was performed and from this, eightythree papers were considered appropriate to include within this review.

Results and Conclusion. Available literature highlights several methods of interventional pain treatment, including spinal cord stimulation and video-assisted upper thoracic sympathectomy which can provide good analgesia whilst improving physical activities and quality of life. The positive effect of spinal cord stimulation on the intensity of pain and quality of life has been confirmed in nine randomized controlled trials. Other potential treatment methods include stellate ganglion blocks, insertion of thoracic epidural or spinal catheters and transcutaneous electrical nerve stimulation. These approaches however appear more useful for diagnostic purposes and perhaps as short-term treatment measures.

Key words: refractory angina, spinal cord stimulation, thoracic sympathectomy, stellate ganglion

Received: February 8, 2014; Accepted: May 22, 2014; Available online: June 19, 2014

http://dx.doi.org/10.5507/bp.2014.028

${ }^{a}$ Department of Anaesthesia and Intensive Medicine, $1^{\text {st }}$ Faculty of Medicine, Charles University in Prague and General University Hospital, Prague, Czech Republic

${ }^{b}$ Department of Cardiology, Na Homolce Hospital, Prague

'Department of Anaesthetics, Antrim Area Hospital, Antrim, United Kingdom

Corresponding author:Pavel Michalek, e-mail: pavel.michalek@vfn.cz

\section{INTRODUCTION}

Refractory angina pectoris (RAP) is defined as a "chronic condition caused by clinically established reversible myocardial ischaemia in the presence of coronary artery disease (CAD) which cannot be adequately controlled by a combination of medical therapy, angioplasty or coronary artery bypass graft" (ref. $\left.{ }^{1}\right)$. There are other clinical syndromes which cause chronic cardiac and non cardiac chest pain - these are summarized in Table 1 (ref. ${ }^{2,3}$ ).

It is estimated that refractory angina affects 600,000 1800,000 people in the United States with approximately 50,000 new patients every year ${ }^{4,5}$. The estimated incidence of new cases per year in continental Europe is 30-50,000 $\left(\right.$ ref. $\left.^{6}\right)$, with an estimated prevalence of refractory angina of 100,000 people in Europe ${ }^{7}$.

RAP usually significantly restricts the physical activities of patients and decreases the overall quality of their lives. Treatment of the RAP should be multidisciplinary and include pharmacotherapy, physiotherapy, psychotherapy, counselling, pain management and treatment of depression if present ${ }^{5,6}$.

Interventional pain management techniques may also play a very important role in the management of RAP in appropriately selected patients. This can involve spinal cord stimulation (SCS) $\left(\right.$ ref. $\left.^{8}\right)$ and other neuromodulation techniques, subcutaneous electrical nerve stimulation (SENS), transcutaneous electrical nerve stimulation
(TENS) (ref. ${ }^{9}$ ), blockade of sympathetic structures ${ }^{10}$ and neuraxial blocks ${ }^{11}$.

Other methods, not commonly seen in the pain clinic, are described as having a positive effect in the management of the RAP, which include enhanced external counterpulsation (EECP) $\left(\right.$ ref. $\left.{ }^{12}\right)$, extracorporal shockwave myocardial revascularization (ESMR) $\left(\right.$ ref. $\left.{ }^{13}\right)$, percutaneous myocardial laser revascularization (PMLR), gene angiogenesis and, theoretically, also heart transplantation. Pharmacological agents currently discussed in the management of RAP include allopurinol, ranolazine, trimetazidine, nicorandil and ivabradine. However these techniques and drugs will not be included in the review.

This review article is focused on interventional methods employed in treatment of chest pain associated with refractory angina.

\section{METHODOLOGY}

An extensive search was performed using the following medical databases - PubMED, Web of Science, Science Direct, Google Scholar and SCOPUS. The following were used as search parameters: "refractory angina", "angina pectoris", "pain management" AND "stellate ganglion block", "thoracic sympathectomy/thoracic sympathetic block", "radiofrequency", "spinal cord stimulation", "nerve stimulation", "paravertebral block", "spinal/epidural block". Selected languages were English, German, 
Spanish and French. In total, 595 articles were identified, of these 205 articles were studied, after careful selection, for the purpose of this review. This literature search of 205 peer review articles identified several interventional management techniques which will each be reviewed. In total, analysis of eighty-three articles is included in this review.

\section{INTERVENTIONAL TECHNIQUES OF PAIN MANAGEMENT IN RAP SYNDROME}

\section{Sympathetic nerve blocks}

When considering RAP, a diagnostic blockade of the lower cervical sympathetic structures or the upper thoracic sympathetic ganglia could be performed if there is a suspected contribution of the sympathetic (vegetative) nervous system in ischaemic myocardial pain ${ }^{14}$.

The sympathetic nervous system is thought to play a significant role during myocardial ischaemia with both sympathetic activation pathways, humoral and neurogenic, being involved. Humoral activation is associated with increased serum catecholamine concentrations while neurogenic activation causes high concentrations of norephinephrine in the heart.

Sympathetic blockade targeted at the innervation of the heart may interrupt both branches (afferent and efferent) of the Malliani's brain and spinal reflexes. The result of this is an abolition of painful stimulus and supression of sympathetic neurogenic activation ${ }^{15}$.

Various techniques of sympathetic blockade, temporary and permanent, have been used in the clinical setting as discussed below.

Stellate ganglion block - this technique is based upon the application of local anaesthetic solution close to the medial cervical sympathetic ganglion or to the cervicothoracic (stellate) sympathetic ganglion ${ }^{16}$. The original techniques of block, use puncture between the carotid artery and cricoid cartilage at the level of C6 - however they may be associated with vertebral artery application, oesophageal puncture or retropharyngeal haematoma ${ }^{17}$. Ultrasound guided puncture allows safe placement of the needle tip under the anterior fascia of the longus colli muscle where the cervical sympathetic chain is normally located ${ }^{18}$. Stellate ganglion block may provide temporary relief from angina symptoms lasting usually for one to four weeks ${ }^{19,20}$. One study describes RF ablations to the stellate ganglion with a long-term effect. However the risk of permanent Horner syndrome should be taken into the account ${ }^{21}$. Stellate ganglion diagnostic block provides useful information prior to thoracic sympathectomy.

A study of Moore et al. evaluated the effect of stellate ganglion blocks on RAP and compared it with thoracic paravertebral blockade. Forty-six patients with RAP underwent left stellate ganglion blocks with bupivacaine. In total 227 blocks was performed. Thirty-one patients (75\%) experienced complete pain relief with a mean pain relief period of 3.48 weeks (SD 3.38) (ref. ${ }^{19}$ ). Rarely, stellate ganglion blockade may provide long-term effect lasting for months to years ${ }^{20}$.
Thoracic paravertebral block - local anaesthetic solution administered into the left paravertebral space at the T2, T3 or T4 levels provides sensory and sympathetic blocks to the segments adjacent to the site of puncture and therefore may provide temporary blockade of sympathetic innervation to the heart. This block has been used in subjects with angina pain since 1925 (F. Mandl). The effect of thoracic paravertebral block on the ECG in 12 patients with angina was studied by Braun. The study showed reversal of ischaemic changes in $66 \%$ after the block. These ECG changes did not always correspond with pain relief ${ }^{22}$. The aforementioned study of Moore et al. has shown reduced efficacy of the paravertebral block compared with the left stellate ganglion blocks ( $52 \%$ vs $75 \%$, mean duration of effect 2.80 weeks versus 3.48 weeks) (ref. ${ }^{19}$ ). Currently, thoracic paravertebral block has been replaced in this indication by more targeted sympathetic blocks.

Video-assisted upper thoracic sympathectomy (VATSY) - this procedure is often performed to treat hyperhidrosis or Raynaud's syndrome. The upper thoracic sympathetic chain is relatively easy located during video-thoracoscopy. The excision of the sympathetic chain can then cause immediate effects, which include decreased heart rate and systemic blood pressure, decreased sweating and increased temperature and perfusion of the upper $\operatorname{limb}^{23}$.

Surgical operations on the sympathetic structures innervating the heart have been performed for over a century (cervical sympathectomy - Alexander, 1889 and cervico-thoracic sympathectomy - Jonnesco, 1920). In 1951, Kux published his experience with thoracoscopic sympathectomy and splanchnicectomy in angina and other indications such as duodenal ulcer, hypertension and diabetes ${ }^{24}$.

In total, six articles exploring the effect of the videoassisted thoracic sympathectomy in patients with angina have been published. Tygesen et al. studied the effect of video-assisted thoracic sympathectomy on the variability of heart rate in 57 patients with severe angina pectoris and showed increased heart rate variability after the procedure which implies a shift of the cardiac autonomic innervation towards parasympathetic dominance ${ }^{25}$. Claes prospectively evaluated the effect of VATS sympathectomy on angina pain in 43 patients and reported that 19 patients (44\%) achieved complete pain relief, 22 (51\%) improved significantly while only two patients $(5 \%)$ did not respond ${ }^{26}$. Another case series reported pain relief in most patients, with concurrent significant reduction in VAS scores and improvement in CCS after VATS sympathectomy ${ }^{27}$. The procedure also provided complete pain relief in four out of five patients with a vasospastic angina refractory to pharmacotherapy ${ }^{28}$. Furthermore ST-segment elevations decreased after the procedure. RAP may therefore be another indication for VATSY where bilateral or unilateral left-sided procedures could be performed.

The procedure may be associated with acute complications such as pneumothorax, haemothorax, chylothorax, oesophageal or lung injury ${ }^{24,26}$. Delayed complications may involve compensatory lower extremity hyperhidrosis, 
Table 1. Causes of chronic chest pain of cardiac and non-cardiac origin.

\begin{tabular}{|c|c|}
\hline Cardiac chest pain & Non-cardiac chest pain \\
\hline $\begin{array}{l}\text { Acute coronary syndrome } \\
\text { - Acute myocardial infarction } \\
\text { - Unstable angina }\end{array}$ & $\begin{array}{l}\text { Pulmonary origin (pneumonia, pulmonary embolism, } \\
\text { pleuritis, pneumothorax, asthma/COPD, acute bronchitis, } \\
\text { lung abscess) }\end{array}$ \\
\hline $\begin{array}{l}\text { Stable angina } \\
\text { Prinzmetal angina, epicardial } \\
\text { coronary vasospasm } \\
\text { Cocaine-induced vasospasm }\end{array}$ & $\begin{array}{l}\text { Musculosceletal (costochondritis, trauma, muscle pain, } \\
\text { post-sternotomy, post-thoracotomy pain, referred pain } \\
\text { from spine, cancer pain-rib, sternum) }\end{array}$ \\
\hline Nocturnal angina & Mediastinal (aortic dissection, mediastinitis) \\
\hline $\begin{array}{l}\text { Decubitus angina } \\
\text { Atypical angina } \\
\text { Chronic refractory angina } \\
\text { Pericarditis }\end{array}$ & $\begin{array}{l}\text { Gastrointestinal (oesophagitis, gastritis, peptic ulcer, } \\
\text { Boerhaave syndrome, oesophageal spasm, cholecystitis, } \\
\text { pancreatitis) }\end{array}$ \\
\hline $\begin{array}{l}\text { Aortic stenosis } \\
\text { Mitral valve prolapse }\end{array}$ & $\begin{array}{l}\text { Other (herpes zoster, postherpetic neuralgia, necrotizing } \\
\text { fascitis) }\end{array}$ \\
\hline $\begin{array}{l}\text { Congenital cardiac anomalies } \\
\text { Cardiac tamponade }\end{array}$ & Psychogenic (panic attacks, anxious state, somatization) \\
\hline
\end{tabular}

source: Fritz, Chronic cardiac chest pain, Contin Educ Anaesth Crit Care Pain 2012;12:302-6 and Verdon, Chest pain in daily practice:occurrence, causes and management, Swiss Med Wkly 2008;138, 340-7.

intrathoracic infection or neuropathic pain due to intercostal nerve trauma.

Radiofrequency (RF) upper thoracic sympathectomy is a minimally invasive percutaneous procedure. An X-ray or CT guidance is employed to navigate an RF probe close to the upper thoracic sympathetic structures at the levels of T2 and T3 on the left side and following stimulation test, radiofrequency energy is applied on the sympathetic nerves and ganglia causing their thermodestruction. Use of this method in the treatment of refractory angina, Prinzmetal's angina or syndrome $\mathrm{X}$ has been documented only in small case series ${ }^{29,30}$. The current main indications for this procedure are hyperhidrosis, complex regional pain syndrome or ischaemic conditions of the upper extremity ${ }^{31,32}$.

\section{Spinal cord stimulation (SCS)}

Spinal cord stimulation is a neuromodulation technique causing an interruption in the perception of painful stimuli from the myocardium. The method of action is not explicitly understood but several theories have been postulated. These theories include a gate-control theory, theories of direct release of beta-endorphines and homogenization of myocardial perfusion via an adenosine activation and reduction in "steal phenomenon"33-35. Initial studies regarding SCS in refractory angina were published in the $1980 \mathrm{~s}^{36,37}$.

Based on the results of clinical and experimental studies it may be postulated that:

- SCS has an antiischaemic effect which is caused by a modulation of the sympathetic nervous system.

- SCS increases the threshold for an angina pain due to a redistribution of a coronary blood flow in the heart.

- SCS causes the release of endogenous neuromedia- tors and substances with neuromodulation properties - mainly endorphines and enkephalines.

- SCS can relieve the symptoms of refractory angina and improve the overall quality of life.

Thus SCS provides a combination of analgesic and antiischaemic effects. In addition, stimulation causes a sensation of vibration which may be pleasant for some patients $^{35}$.

The total number of patients treated worldwide with the SCS for RAP is estimated to be as high as 3500 . This method is widely used mainly in Sweden, Netherlands, Denmark, Switzerland and Italy. It is not commonly used in the United Kingdom or the United States for this indication. The National Institute for Clinical Excellence (NICE) in the UK concludes that SCS may have some positive role in the management of chronic cardiac ischaemic pain but should be performed only in highly specialized centres and as a "last resort" option. In the United States the FDA approves SCS use in chronic pain but not specifically in the RAP.

Spinal cord stimulation has been used in the Czech Republic for the management of refractory angina since 2000. As of (date) a total 35 patients have been implanted.

\section{Results of randomized controlled trials}

In total, nine RCTs have investigated the effect of SCS on patients with refractory angina (Table 2). Studies comparing SCS with placebo or with SCS-off mode showed a decreased incidence of angina attacks, reduced consumption of short-acting nitrates, improved quality of life and increased physical activity in patients treated with active SCS (ref. ${ }^{38-41}$ ).

A recent multicenter study compared three modes of SCS in 25 patients with the RAP. Paraesthetic SCS was compared with a subliminal SCS and a sham. Paraesthetic 
Table 2. Randomized controlled trials evaluating interventional methods in the management of refractory angina pain.

\begin{tabular}{|c|c|c|c|c|c|}
\hline Study & Design & $\begin{array}{l}\text { Patients } \\
\text { (control) }\end{array}$ & Primary outcome & Follow-up & Main findings \\
\hline $\begin{array}{l}\text { SCS } \\
\text { DeJongste, } \\
1994\end{array}$ & $\begin{array}{l}\text { RCT (SCS } \\
\text { vs. control) }\end{array}$ & $8(9)$ & $\begin{array}{l}\text { Exercise capacity } \\
\text { (treadmill test) }\end{array}$ & 8 weeks & $\begin{array}{l}\text { SCS group - higher exercise capacity, better } \\
\text { QOL, reduction in anti-anginal medication }\end{array}$ \\
\hline $\begin{array}{l}\text { Mannheimer, } \\
1998 \\
\text { (ESBY trial) }\end{array}$ & $\begin{array}{l}\text { RCT (SCS } \\
\text { vs. CABG) }\end{array}$ & $53(51)$ & $\begin{array}{l}\text { Exercise tolerance } \\
\text { (workload), number of } \\
\text { angina attacks }\end{array}$ & 6 months & $\begin{array}{l}\text { Adequate relief of symptoms in both groups, } \\
\text { better exercise tolerance in CABG group, } \\
\text { lower mortality and cerebrovascular morbid- } \\
\text { ity in SCS group. }\end{array}$ \\
\hline
\end{tabular}

Hautvast, 1998 RCT (SCS

vs. control)

13 (12) Exercise capacity, number of angina attacks

Jessurun, 1999 RCT (SCS-on vs. SCS-off)

$12(12)$

Number of angina attacks, nitrate use

2 months

Number and duration 48 hours of ischaemic episodes, ischaemic burden

McNab, 2006 RCT (SCS

30 (30) Exercise tolerance (treadmill test)

\section{1,5 months}

Increased exercise duration, time to angina attack, decreased number and duration of angina attacks, decreased nitrate use improved QOL in SCS group.

DiPede, $2001 \quad$ RCT (SCS-on 15 (15)

(SPiRiT trial)

vs. PMR)

Eddicks, 2007 RCT (SCS-on vs. SCS-off)

12 (12) Functional status, 4 weeks Crossover QOL, CCS, nitrate use

Lanza, 2011 RCT (SCS vs (SCS-ITA trial) sublimin. SCS vs sham)

$10(7,8) \quad \begin{aligned} & \text { Number of angina } \\ & \text { episodes }\end{aligned}$

Zipes, 2012

RCT (SCS-on

(STARTSTIM

vs. SCS low

trial) energy)

Incidence of major 6 months cardiac adverse events

VATSY: No RCT

TENS: RCT (TENS

Jessurun, 1998 vs. control)

Börjesson, 1997 RCT (TENS vs. placebo)

$23(18)$

Forearm blood flow

N/A

Hallén, 2010

RCT (TENS

in RAP pa-

tients

vs. healthy)
14 (16) ST changes on ECG, 24 hours elevation in cardiac enzymes
No presence of myocardial ischaemia or increased angina attacks following withholding spinal cord stimulation.

Decreased number and duration of ischaemic periods in SCS-on group, Decreased ischaemic burden in SCS-on group.

No difference between the groups in exercise tolerance, QOL, CCS class.

Improved functional status, QOL, CCS, decreased nitrate use in SCS and sub-treshold SCS compared with placebo.

Decreased number of angina attacks and reduced nitrate use in SCS group at $1 \mathrm{~m}$, decreased incidence in angina attacks in SCS group at $3 \mathrm{~m}$.

Decreased incidence of angina attacks and improved exercise tolerance in both groups, no difference between the groups

Dilation of healthy coronary arteries and decrease in diameter in stenotic artery in TENS group, no changes in control group.

Increase in the forearm blood flow following TENS in healthy controls but not in patients with RAP

Lower incidence of ST changes in TENS group, no difference in duration of ischaemic event or rise in cardiac enzymes

SCS - spinal cord stimulation, TENS - transcutaneous electrical stimulation, RAP - refractory angina pectoris, QOL - quality of life, CCS Canadian Cardiovascular Society Scale

SCS was associated with a significant decrease in angina attacks at 3 months when compared with the other groups ${ }^{42}$. STARTSTIM study compared low stimulation mode with SCS actively delivered by patients and found no difference between the groups in terms of major ad- verse cardiac events. However, patients in both groups experienced reduction in the incidence of angina attacks and reported improved exercise tolerance. This study was terminated early due to difficulties with enrollment and also was underpowered for the primary outcome ${ }^{43}$. 
Table 3. Recommended management of refractory angina pain according to the Guidelines of selected cardiology societies ${ }^{1,80-82}$.

\begin{tabular}{llllll}
\hline Society/Guidelines & SCS & VATSY & SGB & TENS & Others \\
\hline ECS Guidelines (2013) & $\begin{array}{l}\text { may be considered } \\
\text { (IIb, Level B) }\end{array}$ & not assessed & not assessed & $\begin{array}{l}\text { may be considered } \\
\text { (IIb, Level B) }\end{array}$ & $\begin{array}{l}\text { EECP (IIa, Level B) } \\
\text { TMLR not recomm. }\end{array}$ \\
$\begin{array}{llll}\text { CCS/CPS Joint } \\
\text { Guidelines (2012) }\end{array}$ & $\begin{array}{l}\text { may be considered } \\
\text { (WR, MQE) }\end{array}$ & $\begin{array}{l}\text { unable to } \\
\text { evaluate }\end{array}$ & $\begin{array}{l}\text { unable to } \\
\text { evaluate }\end{array}$ & not assessed & $\begin{array}{l}\text { EECP (WR,LQE) } \\
\text { TMLR not recomm. } \\
\text { PMLR (WR,MQE) }\end{array}$ \\
$\begin{array}{llll}\text { Czech Society of Cardiology } \\
\text { Guidelines (2010) }\end{array}$ & may be considered & $\begin{array}{l}\text { may be } \\
\text { considered }\end{array}$ & not assessed & not assessed & TMLR not recomm. \\
$\begin{array}{l}\text { ACC/AHA Guidelines } \\
\text { (2002) }\end{array}$ & $\begin{array}{l}\text { may be considered } \\
\text { (IIb, Level B) }\end{array}$ & not assessed & not assessed & not assessed & TMLR (IIa, Level A) \\
\hline
\end{tabular}

ECS - European Society of Cardiology, CCS - Canadian Cardiovascular Society, CPS - Canadian Pain Society, ACC - American College of Cardiology, AHA - American Heart Association, SCS - spinal cord stimulation, VATSY - video-assisted thoracic sympathectomy, SGB - stellate ganglion block, TENS - transcutaneous electrical nerve stimulation, EECP - enhanced external counterpulsation, TMLR - transmyocardial laser revascularization, PMLR - percutaneous myocardial laser revascularization. SR - strong recommendation, WR - weak recommendation, NR - not recommended, SQE - strong-quality evidence, MQE - moderate-quality evidence, LQE - low-quality evidence.

Two studies compared SCS with another active treatment modality. The ESBY trial compared SCS with CABG in 104 patients (53 pts in the SCS group, 51 pts in the CABG group) with severe angina pectoris for one year period ${ }^{44}$. Both modalities showed similar symptom relief. Patients in CABG group had better exercise capacity and lesser ischaemic changes on ECG during exercise while those in the SCS group experienced lower mortality and cerebrovascular morbidity. The SPiRiT trial compared SCS with the percutaneous myocardial laser revascularization (PMLR) in 68 patients with refractory angina ${ }^{45}$. The authors did not demonstrate any difference in terms of exercise tolerance or overall quality of life between the groups. A meta-analysis of published studies has reported reduced angina attacks in SCS patients from 5.5 to 2.2 within 48 hours $^{35}$.

The ongoing multicenter RASCAL study aims to compare the efficacy and cost-effectiveness of SCS versus standard care in patients with the refractory angina ${ }^{46}$.

\section{Results of non-randomized trials}

Several other studies confirm positive effects of SCS in refractory angina. Greco et al. studied the total incidence of angina attacks in 23 patients with an implanted SCS. Patients experienced in total 4.2 episodes weekly at 1 year after procedure whilst the pre-implant incidence was 9.2 episodes per week $(P<0.01)\left(\right.$ ref. $\left.^{47}\right)$. De Jongste et al. reported a significantly decreased incidence of angina attacks and reduction in total number of ischaemic episodes within 48 hours in patients treated with SCS $\left(\right.$ ref. $\left.{ }^{48}\right)$. Murray concluded that the patients with SCS have a significantly lower incidence of hospital admissions because of cardiac pain than the control group ${ }^{49}$.

A multi-centre cohort study evaluated the mortality rate during study period (128 months) in 517 patients treated in 21 centres. One-year cardiac mortality was 3.5$5 \%$ while total mortality reached $7-8 \%\left(\right.$ ref. $\left.^{50}\right)$.

A register based, non-randomized study compared hospital utilization and total spendings between patients treated with SCS and enhanced external counterpulsation
(EECP) $\left(\right.$ ref. $\left.{ }^{51}\right)$. Both methods improved quality of life, decreased number of hospital admissions and saved costs of treatment. EECP was significantly cheaper than SCS $(P<0.001)$. Result of this study suggests that EECP, as a less invasive method, might replace SCS in treatment of refractory angina pain.

The EARL (European Angina Registry Link) study assessed the long-term effect of SCS on angina attacks, exercise tolerance and overall quality of life ${ }^{7}$. In total, 235 patients were enrolled ( $121 \mathrm{pts}$ had SCS implanted while 114 pts were treated conservatively) and followed-up for a period of 12.1 months. Patients in the SCS group reported a significantly lower incidence of angina attacks $(P<0.0001)$, decreased consumption of short-acting nitrates $(P<0.0001)$ and improvement in the Canadian Cardiovascular Society (CCS) class $(P<0.0001)$. This study assessed also the effect of SCS on the quality of life using Short Form 36 (SF-36) and Seattle Angina (SAQ) questionnaires and showed improved quality of life in patients treated with SCS. Implantation of spinal cord stimulator also decreased the total cost for treatment and hospital stay in patients with the RAP (ref. ${ }^{52}$ ).

SCS may influence function of vital organs, positron-emiting tomography (PET) showed increased perfusion of nociceptive brain areas ${ }^{53}$ and homogenization of myocardial perfusion ("inverse steal phenomenon") in patients with RAP who had spinal cord stimulator inserted ${ }^{54}$. Norssell et al. reported decreased turnover and re-uptake of norepinephrine in patients treated with SCS which may support the hypothesis of total reduction in an adrenergic activity due to SCS ( ref. $^{55}$ ).

A significant improvement of ischaemic symptoms following a spinal cord stimulator implantation and increased exercise tolerance have been shown also in patients with cardiac syndrome $\mathrm{X}$ (angina attacks without coronary artery stenosis) (ref. ${ }^{56}$ ).

Some authors have challenged the fact that SCS may be potentially dangerous because of masking the symptoms of myocardial ischaemia and may therefore cause unrecognized life-threatening cardiac events. This theory 
was refuted by the studies of Andréll and Andersen. Their results imply that the incidence of acute myocardial infarction and sudden cardiac death are not significantly higher in patients with implanted SCS compared to the control group ${ }^{7,57}$

\section{Complications}

Complications associated with spinal cord stimulation are quite frequent, may reach up to $20 \%$ of overall implantations and include electrode migration, electrode displacement or breakage, infections of epidural space or subcutaneous tissues ${ }^{7,58,59}$. Severe complications including spinal canal haematoma are extremely rare.

Contraindications to SCS implantation include bleeding disorders, tumours of the spinal canal, serious autoimmune disorder and failure to obtain patient consent. Another potential limitation of the routine use of SCS is its cost (20-30 000 Euro per patient). However, recent trial has shown that, in the long-term horizon, spinal cord stimulation is cost effective in refractory angina pain when compared with conventional medical management ${ }^{60}$.

\section{Subcutaneous electrical stimulation (SENS)}

This technique was originally used as an additive to spinal cord stimulation. In refractory angina pain it may be used to supplement pain relief provided by epidural electrode or alone in patients where implantation of epidural lead is not feasible. A classical lead (4 or 8 electrodes) is implanted to the subcutaneous tissue usually parallel to the sternum. The region affected by chest pain should be completely covered during stimulation. SENS (or peripheral subcutaneous field stimulation - PSFS) is a technically simple method, which is not associated with the potentially serious complications associated with SCS but this technique requires further evaluation ${ }^{61,62}$. The method has been more extensively studied in patients with low back pain and several mechanisms of action have been proposed. These include antinociceptive effect on the periphery, local vasodilation effect and inhibition of neurotransmitter release or re-uptake at the level of peripheral nervous system ${ }^{63}$.

Only two case series reported improved quality of life and decreased angina attacks following SENS implantation. Buiten et al. report seven patients with SENS decreasing their frequency of angina attacks (by $82 \%$ ), as well as the use of glyceroltrinitrate. Patients also experienced improved quality of life and increased exercise tolerance ${ }^{61}$.

Another case report describes a series of five patients in whom SENS/PSFS provided good pain relief, improvement of symptoms and reduction in pharmacotherapy ${ }^{62}$. Two of these patients had analgesic effect with subcutaneous stimulation where previous SCS had failed.

\section{Transcutaneous electrical nerve stimulation (TENS)}

Transcutaneous electrical nerve stimulation is based on the application of the low intensity electrical current through the skin. Postulated theories of action involve segmental mechanisms (reduction in activity of the cen- tral nociceptive cells due to an induced stimulation of the peripheral A $\delta$ fibers) and extrasegmental mechanisms causing the activation of periaqueductal grey in the midbrain, rostral ventromedial medulla together with an inhibition of descending pathways facilitating pain transmission. Feelings of pain are replaced by vibrations. Some of the positive effects of TENS may be due to a "placebo effect". Swedish researchers pioneered TENS in therapy of refractory angina more than 30 years ago (Table 2) and reported relatively good efficacy associated with minimal invasivity ${ }^{9,64,65}$. The main downfalls include a gradual increase of skin resistance at the site of electrode placement with a decrease in TENS effect, skin irritation due to long-term electrode placement, patient discomfort related to the use of the system (external electrodes, wires, stimulating box, bulkiness). TENS is still used in some countries as a test method before SCS implantation ${ }^{65}$.

Jessurun et al. studied the effect of TENS on coronary blood flow dynamics in 10 patients with NYHA class III angina, while another eight patients were in the control group $^{66}$. The authors did not prove any effect of TENS on the total volumetric flow of the coronary vessels or haemodynamic parameters. Mannheimer et al. studied the effect of TENS on pain relief in patients with refractory angina ${ }^{9}$. The authors showed improved work capacity, reduced incidence of angina attacks and decreased consumption of short-acting nitrates following TENS treatment. Another small case study showed improved quality of life and exercise tolerance in ten patients with refractory angina treated with TENS ( ref $^{67}$ ). Several studies showed decrease in systemic vascular resistance (afterload of the left heart) in patients with angina and syndrome $\mathrm{X}$ treated with TENS (ref., ${ }^{9,68-70}$ ). Decreased vascular resistance may reduce myocardial oxygen consumption and therefore improves oxygen demand/consumption balance. Interesting findings were published by Hallén et al. - in their study TENS caused vasodilation only in healthy control patients but not in those with the refractory angina ${ }^{71}$.

\section{Other interventional methods}

Epidural application of local anaesthetics/opioids - thoracic epidural anaesthesia at the upper and mid-thoracic levels provides blockade of sympathetic innervation of the heart ${ }^{72}$. The blockade may be employed for cardiothoracic procedures helping to maintain perioperative haemodynamic stability and providing excellent postoperative pain relief. Continuous or intermittent epidural analgesia has been considered a palliative technique in selected patients with refractory cardiac pain. Initial report described seven patients who had epidural port system implanted in thoracic region and received intermittent applications of morphine ${ }^{73}$. Patients were followed-up for a period of 3-11 months and reported almost complete pain relief. Blomberg reported a cohort of twenty patients with severe coronary artery disease who underwent long-term analgesic epidural therapy with bupivacaine ${ }^{74}$. Catheters were in situ for a mean period of 6 months and decreased both the incidence and intensity of attacks in most patients. Another case series described the use of high thoracic 
epidural catheter in 10 patients with the refractory angina. Three patients had their catheter inserted for more than 90 days. All patients reported improved symptoms of angina but seven of them $(70 \%)$ still required intravenous nitroglycerin ${ }^{75}$.

The incidence of angina attacks and overall quality of life were evaluated in 37 patients with the RAP treated with a self-application of diluted bupivacaine into tunneled epidural catheter ${ }^{10}$.

Patients were followed up for 1-3 year period. The incidence of angina attacks, nitrate use and CCS class improved during the follow-up period. The authors did not mention any serious adverse effects of treatment except of catheter displacement. Long-term effect of home thoracic epidural analgesia, with a follow-up between one and nine years, was evaluated recently in a cohort of 152 patients with refractory angina ${ }^{76}$. Almost $95 \%$ of subjects reported improved quality of life, reduction in the incidence of angina attacks, better exercise tolerance and lower nitrate consumption. Furthermore, CCS class dropped from 4.0 to 2.0. Main complications were misplacement of epidural catheter in one third of subjects and one case of epidural haematoma.

Andersen and Hole explored the effect of previous long-term epidural catheter on the performance of subsequently inserted spinal cord stimulator using a non-randomized prospective design on 53 patients ${ }^{77}$. They did not find any difference in electrode migration, amplitude of stimulation thresholds or overal effect of SCS between patients treated with previous epidural and control group.

Intrathecal catheters - strong opioids administered intrathecally may modulate refractory angina pain via their effect on spinal cord opioid receptors. Two case series have described this rare method. Segal implanted an intrathecal programmable pump in a patient with frequent attacks of unstable angina pectoris ${ }^{78}$. The patient experienced excellent pain relief and significant improvement of exercise tolerance. Intrathecal morphine application did not mask the symptoms of acute myocardial infartion which occured six months after implantation. Another case series evaluated the effect of long-term epidural or intrathecal morphine (fentanyl) application in seven patients with persistent cardiac pain refractory to pharmacological treatment ${ }^{79}$. Long-term efficacy of the treatment was good with a slight opioid dosage increase over time during an observation period lasting from 2 to 7 years. Most patients however developed unpleasant side effects such as drowsiness, sleep disturbances, urinary retention and sweating. Potential serious complications of intrathecal opioid administration include risk of spinal canal infection or haematoma, meningism and risk of opioid toxicity.

\section{Statement of cardiology societies on the interventional management of refractory angina}

A recent ESC guidelines on stable coronary artery disease, published in 2013, recommended some interventional and other methods of pain management for relief of RAP (ref. ${ }^{1}$ ). They suggest that TENS and SCS may be considered to ameliorate the symptoms of refractory angina. Regarding other methods, the use of EECP is also supported by a relatively strong evidence whilst surgical transmyocardial revascularization should not be used due to risk of possible complications (Table 3) (ref. ${ }^{1}$ ). Joint guidelines from the Canadian Cardiovascular Society and Canadian Pain Society also offer specific advice for the treatment of patients suffering from refractory angina ${ }^{80}$. They suggest that SCS and TENS may be considered as they increase exercise capacity and they are also associated with an improvement in quality of life in addition to the management of pain symptoms. The authors concluded that the evidence for other interventional pain methods such as VATSY, epidural analgesia or stellate ganglion block is not robust enough to make any positive or negative recommendations towards their use (Table 3 ).

Joint American College of Cardiology and American Heart Association (ACC/AHA) guidelines from 2002 discuss only the use of SCS and EECP as promising methods in relieving refractory angina symptoms ${ }^{81}$. These are over a decade old and therefore are not based upon the most up to date information. They also recommended performing surgical transmyocardial laser revascularization (TMLR) (Table 3). However, according to the most recent guidelines this method should be avoided due to a high-risk of serious complications. Guidelines of the Czech Society of Cardiology in addition recommend a multidisciplinary approach for the management of RAP including psychotherapy and depression treatment ${ }^{82}$. Spinal cord stimulation and thoracic sympathectomy are mentioned in the guidelines. The use of EECP is supported whilst TMLR is not felt to be indicated (Table 3 ).

\section{CONCLUSIONS}

Various methods of interventional pain management can play a signifant role in the complex care of patients with the refractory angina. They must be a part of multidisciplinary treatment plan involving effective pharmacotherapy, physiotherapy, cognitive-behavioral therapy and pain interventions. There is a clear evidence supporting the use of spinal cord stimulation in patients with chronic pain of cardiac origin including refractory angina ${ }^{35,80,83}$. Treatment modalities involving the interruption of upper thoracic sympathetic chain or subcutaneous target field stimulation are promising but need further confirmation in the setting of a randomized controlled trial (Table 2). TENS, repeated stellate ganglion blocks or neuraxial techniques may provide temporary pain relief in patients contraindicated for the SCS or other interventional techniques.

\section{ACKNOWLEDGEMENTS}

Authorship contributions: MD, PM, PN, MS: Literature search; MD, PM: Manuscript design; PN, MS: Tables; PJ: Manuscript revision and translation.

Conflict of interest statement: None declared. 


\section{REFERENCES}

1. Task Force members; Montalescot G, Sechtem U, Achenbach S, Andreotti F, Arden C, Budaj A et al. 2013 ESC guidelines on the management of stable coronary artery disease: the Task Force on the management of stable coronary artery disease of the European Society of Cardiology. Eur Heart J 2013;34(38):2949-3003.

2. Fritz AK, Faber P. Chronic cardiac chest pain. Contin Educ Anaesth Crit Care Pain 2012;12(6):302-6.

3. Verdon F, Herzig L, Burnand B, Bischoff T, Pécoud A, Junod M, Mühlemann N, Favrat B. Chest pain in daily practice: ocurrence, causes and management. Swiss Med Wkly 2008;138(23-24):340-7.

4. Fraker TD jr, Fihn SD, Gibbons RJ, Abrams J, Chatterjee K, Daley J. 2007 chronic angina focused update of the ACC/AHA 2002 Guidelines for the management of patients with chronic stable angina: A report of the American College of Cardiology/American Heart Association Task Force on Practice Guidelines Writing Group to develop the focused update of the 2002 guidelines for the management of patients with chronic stable angina. Circulation 2007;116(23):2762-72.

5. De Jongste MJ, Tio RA, Foreman RD. Chronic therapeutically refractory angina pectoris. Heart 2004;90(2):225-30.

6. Mannheimer C, Camici P, Chester MR, Collins A, DeJongste M Eliasson T, Follath F, Hellemans I, Herlitz J, Luscher T, Pasic M, Thelle $D$. The problem of chronic refractory angina: report from the ESC Joint Study Group on the treatment of refractory angina. Eur Heart J 2002;23(5):355-70.

7. Kim MC, Kini A, Sharma SK. Refractory angina pectoris: mechanism and therapeutic options. J Am Coll Cardiol 2002;39(6):923-34.

8. Andréll P, Yu W, Gersbach P, Gillberg L, Pehrsson K, Hardy I, Ståhle A, Andersen C, Mannheimer C. Long-term effects of spinal cord stimulation on angina symptoms and quality of life in patients with refractory angina pectoris - results from the European Angina Registry Link Study (EARL). Heart 2010;96(14):1132-6.

9. Mannheimer C, Carlsson CA, Emanuelsson H, Vedin A, Waagstein $\mathrm{F}$, Wilhelmsson $C$. The effects of transcutaneous electrical nerve stimulation in patients with severe angina pectoris. Circulation 1985;71(2):308-16

10. Khogali SS, Miller M, Rajesh PB, Murray RG, Beattie JM. Video-assisted thoracoscopic sympathectomy for severe intractable angina. Eur J Cardiothorac Surg 1999;16(1):95-8.

11. Richter A, Cederholm I, Jonasson L, Mucchiano C, Uchto M, JanerotSjöberg B. Effect of thoracic epidural analgesia on refractory angina pectoris: long-term home self-treatment. J Cardiothorac Vasc Anesth 2002;16(6):679-84.

12. Arora RR, Chou TM, Jain D, Fleishman B, Crawford L, McKiernan T, Nesto RW. The Multicenter Study of Enhanced Externa CounterPulsation (MUST-EECP): effect of EECP on exercise-induced myocardial ischemia and anginal episodes. J Am Coll Cardiol 1999;33(7):1833-40.

13. Zuozienè G, Laucevičius A, Leibowitz D. Extracorporeal shockwave myocardial revascularization improves clinical symptoms and left ventricular function in patients with refractory angina. Coron Artery Dis 2012;23(1):62-7.

14. Wiener L, Cox JW. Influence of stellate ganglion block on angina pectoris and the post-exercise electrocardiogram. Am J Med Sci 1966;252(3):289-95.

15. Kadowaki MH, Levett JM. Sympathectomy in the treatment of angina and arrhythmias. Ann Thorac Surg 1986;41(5):572-8.

16. Rauck RL. Stellate ganglion block. Tech Reg Anesth Pain Manage 2001;5(1):88-93.

17. Stanton-Hicks M. Complications of sympathetic blocks for extremity pain. Tech Reg Anesth Pain Manage 2007;11(3):148-51.

18. Garneau SY, Deschamps A, Couture P, Levesque S, Babin D, Lambert J, Tardif JC, Perrault LP, Denault AY. Preliminary experience in the use of preoperative echo-guided left stellate ganglion block in patients undergoing cardiac surgery. J Cardiothorac Vasc Anesth 2011;25(1):78-84.

19. Moore R, Groves D, Hammond C, Leach A, Chester MR. Temporary sympathectomy in the treatment of chronic refractory angina.J Pain Symptom Manage 2005;30(2):183-91.

20. Chester M, Hammond C, Leach A. Long-term benefits of stellate ganglion block in severe chronic refractory angina. Pain 2000;87(1):103-5
21. ForouzanfarT, van Kleef M, Weber WE. Radiofrequency lesions of the stellate ganglion in chronic pain syndromes: retrospective analysis of clinical efficacy in 86 patients. Clin J Pain 2000;16(2):164-8.

22. Braun K. Paravertebral block and the electrocardiogram in angina pectoris. Br Heart J 1946;8(1):47-52.

23. Wettervik C, Claes G, Drott C, Emanuelsson H, Lomsky M, Radberg $\mathrm{G}$, Tygesen $\mathrm{H}$. Endoscopic transthoracic sympathicotomy for severe angina. Lancet 1995;345(1):97-8.

24. Kux E. The endoscopic approach to the vegetative nervous system and its therapeutic possibilities; especially in duodenal ulcer, angina pectoris, hypertension and diabetes. Dis Chest 1951;20(2):139-47.

25. Tygesen $H$, Claes G, Drott $C$, Emanuelsson H, Lomsky M, Lurje L, Radberg G, Wennerblom B, Wettervik C. Effect of endoscopic transthoracic sympathicotomy on heart rate variability in severe angina pectoris. Am J Cardiol 1997;79(11):1447-52.

26. Claes G, Drott C, Wettervik C, Tygesen H, Emanuelsson H, Lomsky M, Radberg G. Angina pectoris treated by thoracoscopic sympathectomy. Cardiovasc Surg 1996;4(6):830-1.

27. Stritesky M, Dobias M, Demes R, Semrad M. Endoscopic thoracic sympathectomy - its effect in the treatment of refractory angina pectoris. Interact Cardio Vasc Thorac Surg 2006;5(4):464-8.

28. Yoshida K, Inoue T, Hirakawa N, Node K. Endoscopic thoracic sympathectomy as a novel strategy for vasospastic angina refractory to medical treatments. J Cardiol 2008;52(1):49-52.

29. Wilkinson HA. Radiofrequency percutaneous upper-thoracic sympathectomy. Technique and review of indications. N Eng J Med 1984;311(1):34-6.

30. Wilkinson HA. Percutaneous radiofrequency upper thoracic sympathectomy. Neurosurgery 1996;38(4):715-25.

31. Gabrhelik T, Michalek P, Adamus M, Berta E. Percutaneous upper thoracic radiofrequency sympathectomy in Raynaud phenomenon: a comparison of $\mathrm{T} 2 / \mathrm{T} 3$ procedure versus T2 lesion with phenol application. Reg Anesth Pain Med 2009;34(5):425-9.

32. Gabrhelik T, Stehlik D, Adamus M, Zalesak B, Michalek P. Radiofrequency upper thoracic sympathectomy in the treatment of critical upper limb ischemia - a case series. Biomed Pap Med Fac Univ Palacky Olomouc Czech Repub. 2013;157(2):202-8. doi: 10.5507/bp.2011.055

33. Börjesson M, Andréll $P$, Mannheimer C. Spinal cord stimulation for long-term treatment of severe angina pectoris: what does the evidence say? Future Cardiol 2011;7(6):825-33.

34. De Jongste MJ. Spinal cord stimulation for ischemic heart disease. Neurol Res 2000;22(3):293-8.

35. Taylor RS, de Vries J, Buchser E, de Jongste MJ. Spinal cord stimulation in the treatment of refractory angina: systematic review and meta-analysis of randomised controlled trials. BMC Cardiovasc Disord 2009;9(1):13.

36. Murphy DF, Giles KE. Dorsal column stimulation for pain relief from intractable angina pectoris. Pain 1987;28(3):365-8.

37. Mannheimer C, Augustinsson LE, Carlsson CA, Manhem K, Wilhelmsson C. Epidural spinal electrical stimulation in severe angina pectoris. Br Heart J 1988;59(1):56-61.

38. Di Pede F, Zuin G, Giada F, Pinato G, Turiano G, Bevilacqua M, Cazzin $\mathrm{R}$, Raviele $\mathrm{A}$. Long-term effects of spinal cord stimulation on myocardial ischemia and heart rate variability: results of a 48-hour ambulatory electrocardiographic monitoring. Ital Heart J 2001;2(9):690-5.

39. Hautvast RW, DeJongste MJ, Staal MJ, van Gilst WH, Lie KI. Spinal cord stimulation in intractractable angina pectoris: A randomized controlled efficacy study. Am Heart J 1998;136(6):1114-20.

40. Jessurun GA, DeJongste MJ, Hautvast RW, Tio RA, Brouwer J, van Lelieveld S, Crijns HJ. Clinical follow-up after cessation of chronic electrical neuromodulation in patients with severe coronary artery disease: a prospective randomized controlled study on putative involvement of sympathetic activity. Pacing Clin Electophysiol 1999:22(10):1432-9.

41. Eddicks S, Maier-Hauff K, Schenk M, Müller A, Baumann G, Theres $H$. Thoracic spinal cord stimulation improves functional status and relieves symptoms in patients with refractory angina pectoris: the first placebo-controlled randomised study. Heart 2007;93(5):585-90.

42. Lanza GA, Grimaldi R, Greco S, Ghio S, Sarullo F, Zuin G, De Luca A, Allegri M, Di Pede F, Castagno D, Turco A, Sapio M, Pinato G, Cioni B, Trevi G, Crea F. Spinal cord stimulation for the treatment of refractory angina pectoris: a multicenter randomized single-blind study (the SCS-ITA trial). Pain 2011;152(1):45-52. 
43. Zipes DP, Svorkdal N, Berman D, Boortz-Marx D, Henry T, Lerman A Ross E, Turner M, Irwin C. Spinal cord stimulation therapy for patients with refractory angina who are not candidates for revascularization. Neuromodulation 2012;15(6):550-9.

44. Mannheimer $C$, Eliason $T$, Augustinsson LE, Blomstrand $C$, Emanuelsson H, Larsson S, Norrsell H, Hjalmarsson A. Electrical stimulation versus coronary artery bypass surgery in severe angina pectoris: the ESBY study. Circulation 1998;97(12):1157-63.

45. McNab D, Khan SN, Sharples LD, Ryan JY, Freeman C, Caine N, Tait S, Hardy I, Schofield PM. An open-label, single-centre, randomized trial of spinal cord stimulation vs. percutaneous myocardial laser revascularization in patients with refractory angina pectoris: the SPiRiT trial. Eur Heart J 2006;27(9):1048-53.

46. Eldabe S, Raphael J, Thomson S, Manca A, de Belder M, Aggarwal R, Banks M, Brookes M, Merotra S, Adeniba R, Davies E, Taylor RS. The effectiveness and cost-effectiveness of spinal cord stimulation for refractory angina (RASCAL study): study protocol for a pilot randomized controlled trial. Trials 2013;14(1):57

47. Greco S, Auriti A, Fiume G, Gazzeri G, Gentilucci G, Antonini L, Santini M. Spinal cord stimulation for the treatment of refractory angina pectoris: a two-year follow-up. Pacing Clin Electrophysiol 1999;22(1):28-32.

48. De Jongste MJ, Haaksma J, Hautvast RW, Hillege HL, Meyler PW, Staal MJ, Sanderson JE, Lie KI. Effects of spinal cord stimulation on myocardial ichaemia during daily life in patients with severe coronary artery disease: a prospective ambulatory electrocardiographic study. Br Heart J 1994;71(5):413-8.

49. Murray S, Carson KG, Ewings PD, Collins PD, James MA. Spinal cord stimulation significantly decreases the need for acute hospital admission for chest pain in patients with refractory angina pectoris. Heart 1999;82(1):89-92.

50. TenVaarwerk IA, Jessurun GA, DeJongste MJ, Andersen $C$ Mannheimer C, Eliasson T, Tadema W, Staal M. Clinical outcome of patients treated with spinal cord stimulation for therapeutically refractory angina pectoris. TheWorking Group on Neurocardiology. Heart 1999;82(1):82-8.

51. Bondesson SM, Jakobsson U, Edvinsson L, Hallberg IR. Hospital utilization and costs for spinal cord stimulation compared with enhanced external counterpulsation for refractory angina pectoris. $J$ Eval Clin Pract 2013;19(1):139-47.

52. Yu W, Maru F, Edner M, Hellström K, Kahan T, Persson H. Spinal cord stimulation for refractory angina pectoris: a retrospective analysis of efficacy and cost-benefit. Coron Art Dis 2004;15(1):31-7.

53. Hautvast RW, Ter Horst GJ, DeJong BM, DeJongste MJ, Blanksma PK, Paans AM, Korf J. Relative changes in regional cerebral blood flow during spinal cord stimulation in patients with refractory angina pectoris. Eur J Neurosci 1997:9(6):1178-83.

54. Hautvast RW, Blanksma PK, De Jongste MJ, Pruim J, van der Wall EE, Vaalburg W, Lie KI. Effect of spinal cord stimulation on myocardial blood flow assessed by positron emission tomography in patients with refractory angina pectoris. Am J Cardiol 1996;77(7):462-7.

55. Norrsell $\mathrm{H}$, Eliasson $\mathrm{T}$, Manheimer $\mathrm{C}$, Augustinsson LE, Bergh $\mathrm{CH}$, Andersson B, Waagstein F, Friberg P. Effect of pacing-induced myocardial stress and spinal cord stimulation on whole body norepinephrine spillover. Eur Heart J 1997;18(12):1890-6.

56. Spinelli A, Lanza GA, Calcagni ML, Sestito A, Squeglia GA, Di Monaco A, Bruno I, Lamendola P, Barone L, Giordano A, Crea F. Effect of spinal cord stimulation on cardiac adrenergic nerve function in patients with cardiac syndrome X. J Nucl Cardiol 2008;15(6):804-10.

57. Andersen $\mathrm{C}$, Hole $\mathrm{P}$, Oxhoj $\mathrm{H}$. Does pain relief with spinal cord stimulation for angina conceal myocardial infarction? Br Heart 1994:71(5):413-8.

58. Eliasson T, Jern S, Augustinsson LA, Mannheimer C. Safety aspects of spinal cord stimulation in severe angina pectoris. Cor Art Dis 1994;5(10):845-50.

59. Sanderson JE, Ibrahim B,Waterhouse D, Palmer RB. Spinal electrica stimulation for intractable angina - long term clinical outcome and safety. Eur Heart J 1994;15(6):810-4.

60. Kumar K, Rizvi S. Cost-effectiveness of spinal cord stimulation therapy in management of chronic pain. Pain Med 2013;14(11):1631-49.

61. Buiten MS, DeJongste MJ, Beese U, Kliphuis C, Durenkamp A, Staal MJ. Subcutaneous electrical nerve stimulation: a feasible and new method for the treatment of patients with refractory angina. Neuromodulation 2011;14(3):258-65.
62. Goroszeniuk T, Pang D, Al-Kaisy A, Sanderson K. Subcutaneous target stimulation - peripheral subcutaneous field stimulation in the treatment of refractory angina: preliminary case reports. Pain Practice 2012;12(1):71-9.

63. Levy RM. Differentiating the leaves from the branches in the tree of neuromodulation: the state of peripheral nerve field stimulation. Neuromodulation 2011;14(3):201-5.

64. Borjesson M, Eriksson P, Dellborg M, Eliasson T, Mannheimer G. Transcutaneous electrical nerve stimulation in unstable angina pectoris. Coron Artery Dis 1997;8(8-9):543-50.

65. Borjesson M. Visceral chest pain in unstable angina pectoris and effects of transcutaneous electrical nerve stimulation (TENS): a review. Herz 1999;24(2):114-25.

66. Jessurun GA, Tio RA, De Jongste MJ, Hautvast RW, Den Heijer $P_{\text {, }}$ Crijns HJ. Coronary blood flow dynamics during transcutaneous electrical nerve stimulation for stable angina pectoris associated with severe narrowing of one major coronary artery. Am J Cardiol 1998;82(8):921-6.

67. Mannheimer C, Carlsson CA, Vedin A, Wilhelmsson C. Transcutaneous electrical nerve stimulation (TENS) in angina pectoris. Pain 1986;26(3):291-300.

68. Mannheimer C, Carlsson CA, Ericsson K, Vedin A, Wilhelmsson C. Transcutaneous electrical nerve stimulation in severe angina pectoris. Eur Heart J 1982;3(4):297-302.

69. Jessurun GA, Hautvast RW, Tio RA, de Jongste MJ. Electrical neuromodulation improves myocardial perfusion and ameliorates refractory angina pectoris in patients with syndrome X: fad or future? Eur J Pain 2003;7(6):507-12.

70. Sanderson JE, Woo KS, Chung HK, Chan WW, Tse LK, White HD. The effect of transcutaneous electrical nerve stimulation on coronary and systemic haemodynamics in syndrome X. Coron Artery Dis 1996;7(7):547-52.

71. Hallén K, Hrafnkelsdóttir T, Jern S, Biber B, Mannheimer C, Roy SD. Transcutaneous electrical nerve stimulation induces vasodilation in healthy controls but not in refractory angina patients. J Pain Symptom Manage 2010;40(1):95-101.

72. Blomberg S, Emanuelsson H, Kvist H, Lamm C, Pontén J, Waagstein F, Ricksten SE. Effects of thoracic epidural anesthesia on coronary arteries and arterioles in patients with coronary artery disease. Anesthesiology 1990;73(5):840-7.

73. Clemensen SE, Thayssen P, Hole P. Epidural morphine for outpatients with severe anginal pain. Br Med J (Clin Res Ed) 1987;294(6570):4756.

74. Blomberg SG. Long-term home self-treatment with high thoracic epidural anesthesia in patients with severe coronary artery disease. Anesth Analg 1994;79(3):413-21.

75. Gramling-Babb P, Miller MJ, Reeves ST, Roy RC, Zile MR. Treatment of medically and surgically refractory angina pectoris with high thoracic epidural analgesia: initial clinical experience. Am Heart J 1997;133(6):648-55.

76. Richter A, Cederholm I, Fredrikson M, Mucchiano C, Traff S, JanerotSjoberg B. Effect of long-term thoracic epidural analgesia on refractory angina pectoris: a 10-year experience. J Cardiothorac Vasc Anesth 2012;26(5):822-8.

77. Andersen C, Hole P. Long-term home treatment with epidural analgesia does not affect later spinal cord stimulation in patients with otherwise intractable angina pectoris. Clin J Pain 1998;14(4):315-9.

78. Segal R, Murali S, Tipton K. Treatment of chronic unstable angina pectoris: use of a totally implantable programmable device for continuous intrathecal infusion of opiates: case report. Neurosurgery 1996;38(2):385-8.

79. Cherry DA, Gourlay GK, Eldredge KA. Management of chronic intractable angina - spinal opioids offer an alternative therapy. Pain 2003;102(1-2):163-6.

80. McGillion M, Arthur HM, Cook A, Carroll SL, Victor JC, L'Allier $\mathrm{PL}$. Management of patients with refractory angina: Canadian Cardiovascular Society/Canadian Pain Society joint guidelines. Can J Cardiol 2012;28(Suppl 2):S20-41.

81. Committee Members; Gibbons RJ, Abrams J, Chatterjee K, Daley J, Deedwania PC, Douglas JS et al. ACC/AHA 2002 guideline update for the management of patients with chronic stable angina - summary article: a report of the American College of Cardiology/American Heart Association Task Force on Practice Guidelines (Committee on the Management of Patients with Chronic Stable Angina). Circulation 2003;107(1):149-58. 
82. Hradec J, Bultas J, Zelizko M. Stable angina pectoris. Recommendations for diagnosis and treatment of the Czech Society of Cardiology. Cor Vasa 2010;52(9):543-61. [article in Czech]

83. Rasmussen MB, Hole P, Andersen C. Electric spinal cord stimulation (SCS) in the treatment of angina pectoris: a cost-utility analysis. Neuromodulation 2004;7(1):89-96.

\section{Letter to the editor:}

Paz Y, Shinfeld A. Letter to the editor. Re: "Interventional treatment of pain in refractory angina. A review" by Milos Dobias et al. Biomed Pap Med Fac Univ Palacky Olomouc Czech Repub 2014 Jun 19. doi: 10.5507/bp.2014.028. Biomed Pap Med Fac Univ Palacky Olomouc Czech Repub. 2014, 158;486-487, DOI: 10.5507/bp.2014.047 